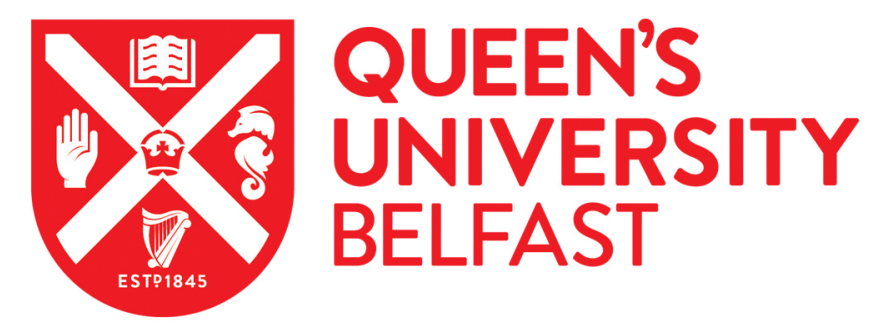

\title{
Deciphering the performance hints hidden in J. S. Bach's quaver beams
}

Tomita, Y. (2016). Deciphering the performance hints hidden in J. S. Bach's quaver beams. Early Music, 44(1), 89-104. https://doi.org/10.1093/em/caw010

\section{Published in: \\ Early Music}

\section{Document Version:}

Early version, also known as pre-print

Queen's University Belfast - Research Portal:

Link to publication record in Queen's University Belfast Research Portal

\section{Publisher rights}

Copyright 2016 The Author

This article has been accepted for publication in Early Music Published by Oxford University Press.

\section{General rights}

Copyright for the publications made accessible via the Queen's University Belfast Research Portal is retained by the author(s) and / or other copyright owners and it is a condition of accessing these publications that users recognise and abide by the legal requirements associated with these rights.

Take down policy

The Research Portal is Queen's institutional repository that provides access to Queen's research output. Every effort has been made to ensure that content in the Research Portal does not infringe any person's rights, or applicable UK laws. If you discover content in the Research Portal that you believe breaches copyright or violates any law, please contact openaccess@qub.ac.uk. 


\title{
Deciphering J. S. Bach's performance hints hidden in his quaver beams $^{1}$
}

\author{
Yo Tomita
}

In Memory of Christopher Hogwood (1941-2014)

Among the many fine qualities attributed to Johann Sebastian Bach and his music is his beautiful musical calligraphy. The widely disseminated facsimile editions of the fair copies of the Solos for Unaccompanied Violin, Inventions and Sinfonias and the first book of The WellTempered Clavier are such exquisite examples of Western musical calligraphy that they have almost come to represent the composer himself. As an eminent teacher as well as prolific composer Bach’s neat handwriting would have been highly advantageous in helping him achieve his goals, in allowing his students to make accurate copies of his scores, and his assistants to make performance parts from them. While it is not possible to say how decisive a role his handwriting played in securing new jobs ${ }^{2}$ or honorary titles, ${ }^{3}$ it undoubtedly contributed to his successful career as a practical musician.

Bach’s autograph manuscripts and the prints for which he supposedly supplied the Stichvorlage (engraver's copy) have shown scholars that Bach was a methodical worker, who continuously developed and perfected his compositions. Bach's manuscripts are a treasure trove of information providing valuable insights into his approach to composition. As a neat and economic writer and to avoid wasting paper, he would calculate the space on the paper in front of him before committing anything to the page. Whether he was composing, revising, or the preparing a fair copy, the disposition of space can usually be seen in his score layout and fascicle structure. Further diplomatic clues in the manuscripts, such as watermarks and the details of his calligraphic formation, are highly important in helping to build an image of

\footnotetext{
${ }^{1}$ This article is a revised version of a paper read at the 1st International Keyboard Music Conference held at the University of Edinburgh in July 2011. Reproductions of the images of Bach's Well-Tempered Clavier, books 1 and 2 are by kind permission of the Staatsbibliothek zu Berlin and The British Library London respectively. The author wishes to thank Jack Ashworth, Jean and Jesper Christensen, Seow-Chin Ong, Ruth Tatlow, Douglas Shadle and Tanja Kovačević for their comments on the earlier version of this paper.

${ }^{2}$ The fair copy of the so-called 'Brandenburg Concertos' was dedicated to Margrave Christian Ludwig. In the accompanying dedication dated 24 March 1721, Bach seeks employment from the Margrave. Nothing is known about the outcome of this request. See The new Bach reader: a life of Johann Sebastian Bach in letters and documents, eds. H. T. David and A. Mendel, rev. and enl. C. Wolff (New York, 1998), pp. 91-3.

${ }^{3}$ The Missa, BWV $232^{\mathrm{I}}$ (Sächsische Landesbibliothek - Staats- und Universitätsbibliothek Dresden, Mus. 2405D-21), was submitted to the newly-installed Elector of Saxony on 27 July 1733 whom Bach approached for the appointment to the position of royal court composer, a request which was he was not granted until three years later. See The New Bach Reader, pp. 158 and 188. The majority of this set of parts is in Bach's hand.
} 
Bach's intentions, and supplement the lack of written records that might otherwise give background information about his compositions, for keyboard in particular. In this article I will show that there is still an abundance of information yet to be extracted from his manuscripts, specifically Bach’s quaver beaming, which when interpreted will reveal more about Bach's compositional and performance decisions as he wrote them out.

That quaver beaming in Bach's autograph manuscripts is a valuable subject to study has been established. In 2011 against a broader background of Bach’s notational practice I was able to demonstrate the values for both performers and editors of critical editions of quaver beaming. ${ }^{4}$ In this article, I shall go one step further and demonstrate that Bach's quaver beams reflect how Bach responded to his pieces in composition and performance, and explore whether or not there is a more rational explanation of the anomalies in Bach's notation in his original manuscripts and prints. This has never been pursued thoroughly before and it promises to uncover the ideas that guided his notational practice and his spontaneous responses to the challenges he faced while writing out the music on paper. Bach often beamed his quavers beyond the beat-unit indicated by the time-signature, as if to indicate the way he perceived, phrased or articulated a musical line. In this essay I will analyse Bach's quaver beaming and consider what the observations imply for Bach's intentions for the performance, aiming to bring Bach's thoughts and intentions closer to the performer.

\section{General principles of quaver beaming in Bach's autographs}

Reproduced in ex.1 is the first page of Bach's autograph of the G-minor Fugue of WTC II, dating from ca.1739-40. ${ }^{5}$ In bar 23 (the last bar of the fifth system in ex.1) six quavers are joined by a single beam in the tenor. They belong to the redundant subject entry, and their beaming follows the form used in first statement of the subject in bar 4. However, in bars 2427 (sixth system of ex.1) the quavers in the bass are beamed in groups of two. Why did Bach notate these quavers differently from those belonging to subject entries? Is it significant that the shorter beaming is found in the episode rather than in the fugue subject? Is pitch a determining factor, with leaps attracting shorter beaming while repeated notes or scalic progressions use longer beaming? Or is the peculiar beaming here a characteristic of his notation at a specific period of his life?

\footnotetext{
${ }^{4}$ Yo Tomita, 'Reading soul from manuscripts: some observations on performance issues in J. S. Bach's habits of writing his music', Essays in honor of Christopher Hogwood: the maestro's direction, ed. T. Donahue (Lanham, 2011), pp. 13-40.

${ }^{5}$ Yoshitake Kobayashi, 'Zur Chronologie der Spätwerke Johann Sebastian Bachs: Kompositions- und Aufführungstätigkeit von 1736 bis 1750’, Bach-Jahrbuch, lxxiv (1988), p. 46.
} 
The last proposition can be ruled out as a similar observation can be made in WTC I, copied twenty years earlier than its younger counterpart WTC II. Ex.2 shows the first page of the B-minor Fugue from Bach’s autograph fair copy of 1722. Bach notated the fugue subjects in the exposition with extended beams over groups of four quavers: only in the fourth entry in the soprano in bars 13-15 (from the third to the fourth system in ex.2) does the pattern of beaming become irregular; in the next entry in the alto from bar 21 (at the beginning of the sixth system in ex.2), the beaming is likewise not consistently preserved in the remainder of the subject entry (viz. bars 22-23). Looking outside of the subject entries, at material belonging primarily to the episodes, we find quavers beamed in groups of two in the bass part in bars 17-20, 23 and 26-27, which is consistent with the observations found in the G-minor fugue of WTC II. The occurrence of shorter beams in the bass is another feature that the two examples have in common. However, the first point, namely that Bach noted the fugue subjects of the B-minor fugue with extended beams, is of more interest as it supports the earlier observation in the G-minor Fugue that longer quaver beams were used for the fugue subject, while the shorter were for the episodes, even though both the fugue subject and the bass line in the episodes are made up of the same motivic material consisting of large leaps. This is indicative of the composer's preference for distinguishing between the types of thematic material rather than responding naturally to melodic contours. The fact that the beam length is not entirely consistent in the B-minor fugue of WTC I may be related to the dilemmas Bach was faced with as a consequence of such prioritisation. But this will be revisited more carefully later.

\section{[insert ex.1]}

Ex.1 Fugue 16 in G minor, WTC II, autograph (@ The British Library Board, Add. MS 35021, f.12v): bars 1-31 [insert ex.2]

Ex.2 Fugue 24 in B minor, WTC I, autograph, (Staatsbibliothek zu Berlin, Mus. ms. Bach P 415, f. 44v): bars 1-27

\section{Previous discussions on beaming}

The issue of beaming, with specific reference to its implications on phrasing and articulation, has been noted many times since the early 1970s by scholars studying the compositions of Frescobaldi, Sweelinck, Johann Caspar Kerll, John Blow, Scarlatti and Rameau. ${ }^{6}$ We are also informed that beaming was used in a more imaginative and distinct way to indicate phrasing and articulation by composers after Bach; composers such as J. C. Bach, Mozart, Beethoven, Schumann, and Brahms, who took the idea of phrasing and articulation of the melody to a

\footnotetext{
${ }^{6}$ For details, see Tomita, ‘Reading soul from manuscripts’, pp. 14-15.
} 
new level. ${ }^{7}$ However in Bach studies the question of beaming has not yet been fully addressed. The editors of the Neue Bach-Ausgabe, for example, normalised inconsistencies in Bach's beaming, treating it as something that required editorial arbitration, ${ }^{8}$ in contradiction to their editorial guideline which advises editors to retain Bach's own grouping of notes with beams as it may convey articulation. ${ }^{9}$ This is not to say that the potential value of information hidden in the quaver beaming was not known to Bach scholars. In the 1994 Associated Board edition of WTC, its editor Richard Jones preserved the beaming of the primary source for the movement he had chosen with all the inconsistencies therein, but without fully establishing the reasons behind this decision or stating the value of doing so. ${ }^{10}$

When working on the revised edition of Bach's WTC II for Henle in 2006, I realised that there seemed to be 'fine nuances' in the notational forms of Bach's quaver beams, which begged further study but conceded then that it was too vast a question to answer satisfactorily in the restricted space of an editorial preface. ${ }^{11}$ Certain occurrences persuaded me that Bach intended to indicate a musical nuance through his choice of beaming, while other less convincing examples left me wondering if Bach had a rigorous system at all.

\section{Bach's quaver beams - norms and exceptions}

Like many other composers of his time, Bach made use of beams to construct notational units of beat within the given time-signature. This visually clarifies the metrical structure of the piece. Semiquavers and smaller notes are almost always beamed in a beat-unit (hereafter referred to as 'default' beaming), ${ }^{12}$ whereas quavers are very often found in a longer unit, viz.

\footnotetext{
${ }^{7}$ See Clive Brown, Classical \& Romantic performing practice 1750-1900 (New York, 1999), pp. 41-6.

${ }^{8}$ See NBA V/6.2 (1995), p. 96 (compare ex.1) and V/6.1 (1989), p. 119 (compare ex.2) respectively.

9 'Da die Bachsche Notengruppierung unter Umständen für die Artikulation von Bedeutung ist, ist sie nach Möglichkeit beizubehalten.' See the section 'Balkensetzung' in 'Editionsrichtlinien. Johann Sebastian Bach. Neue Ausgabe sämtlicher Werke’, Editionsrichtlinien musikalischer Denkmäler und Gesamtausgaben, ed. G. von Dadelsen (Kassel, 1967), pp. 61-80, here p. 66; revised and updated version in Frauke Heinze and Uwe Wolf, Gesamtregister, [NBA IX/4] (Kassel, 2010), p. 325.

${ }^{10}$ J. S. Bach. The Well-Tempered Clavier, Part I. BWV 846-869 [and Part II. BWV 870-893], ed. R. Jones (London: ABRSM, 1994).

${ }^{11}$ Johann Sebastian Bach: Das Wohltemperierte Klavier Teil II, BWV 870-893, ed. Y. Tomita (Munich: G. Henle, 2007), p. ix.

${ }^{12}$ Exceptions, as far as I am aware, are small in number. Some are found in the Violin Partita in D minor (BWV 1004): Sarabande, bar 22 (as ....... ), and Ciaccona, bar 85-9, where the beat is frequently split into two as .$\overline{\equiv . . . .}$. There are two noteworthy examples in the $4^{\text {th }}$ Brandenburg concerto (BWV 1049): in bars 68-69 of the 2nd movement, in the flute part, two semiquaver runs are beamed as groups of 11 and 12 notes respectively (but all 23 notes are joined by a single slur); in bars 101-105 of the 3rd movement, in the solo violin, all 16 semiquavers are placed under one beam and a single slur in each bar, perhaps implying legato playing. A few examples can be found in the original edition of the Keyboard Partitas: BWV 828/1, bar 18, $1^{\text {st }}$ time repeat (16 demisemiquavers beamed together), bars 36-40 and 54 (beaming 17 and 18 semiquavers respectively), BWV 828/4 (frequently beaming 8 semiquavers together), and BWV 829/1 (frequently beaming 12 semiquavers together). Note that issues relating to the beaming of semiquavers predominantly concern hand distribution. See Peter Williams, 'Two case studies in performance practice and the details of notation: 2: J. S. Bach and lefthand-right-hand distribution', Early Music, xxii/1 (Feb 1994), pp. 101-13. Other debates consider the
} 
two beats in $2 / 4$ or $4 / 4$, and three beats in the case of $3 / 4$ (hereafter referred to as 'extended' beaming), as summarised in table $1 .^{13}$ For example, Bach's normal beaming throughout his life in 2/4 time connects all four quavers in a bar (or three if the melody includes a rest), and only under exceptional circumstances does he beam two quavers at a time to coincide with the beat unit indicated by the time-signature.

Table 1 Bach's convention of quaver beaming

[insert table 1]

It is not clear how Bach come to adopt this peculiar beaming practice. Although widely used in music Bach's time, I have so far been unable to trace it in the theoretical treatises of the seventeenth and eighteenth centuries. Manuscript and printed sources from composers working in Bach's sphere generally show that a bar in common time-signature (c) has two extended quaver beams through which the two stresses inherent in the metrical structure of the bar are clarified. ${ }^{14}$ In compound times such as $6 / 16$ and $12 / 16$, a similar rule is applied at the dotted-quaver level.

In $3 / 4$ time Bach normally uses the extended form $\ldots \ldots \ldots$ and not the split-beam default.. ..... hinting that the whole bar should be regarded as a single unit. Occasionally, when he introduces semiquavers, the default form ... . . . . becomes the norm (e.g. WTC II: Prelude in C and Fugues in C, C-sharp, and D minor). The exception to this is the Prelude in F-sharp major of WTC II where Bach used the dotted-rhythm pattern in the extended-beam form . ... .. . ; however, in this movement plain-beam quavers (e.g. ..... ) are not used. When using two demisemiquavers in place of a semiquaver, Bach always breaks up the beam

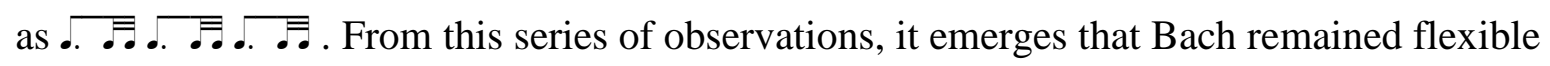
with the length of beaming when combining quavers with semiquavers in 3/4 time, as summarised in table 2. ${ }^{15}$

Table 2 Bach's notation of quaver-semiquaver/demisemiquaver combinations in 3/4 time [insert table 2]

\footnotetext{
implications of the calligraphic shapes of beams (wavy or straight) and the expression of melismas (see, for example, Joel Lester, Bach's works for Solo Violin: style, structure, performance, Oxford, 1999, p. 17).

${ }^{13}$ Time-signatures such as $2 / 2,3 / 2,6 / 4,3 / 8,6 / 8,9 / 8,12 / 8$, in which the length of quaver beams does not vary, are excluded from this table.

${ }^{14}$ Such a theory is credible insofar as we are yet to find even a single example in Bach's hand where an extended quaver beam is used to join beats 2 and 3 .

${ }^{15}$ See Tomita, 'Reading Soul from Manuscripts', pp. 23-5, for further discussion of Bach’s beaming of quaversemiquaver combinations and an illustration of how careful source-based enquiry reveals Bach’s revisions.
} 
Having established Bach’s norms, we can now consider the exceptions and see what his spontaneous reactions to either musical or notational features of the movement can tell us about his intentions for the performance.

\section{Bach's two types of quaver beaming - appearance and significance}

Whenever the exceptions appear in a piece, their role or significance can be evaluated against one of the following scenarios:

1. the exceptions appear fairly consistently in the movement as if they manifest the character (i.e. speed and mood) of the piece, 'character beaming';

2. the exceptions appear together with norms in consistent patterns, suggesting that Bach intentionally distinguished between the two types of figures as if to convey specific musical ideas, 'musical beaming';

3. the exceptions appear together with norms, but no apparent musical reasons behind the variation can be discerned, 'unintelligible beaming'.

The appearance of beaming as if to manifest character, 'character beaming', is found in a small number of movements and seems sufficiently straightforward to read Bach's intentions: the short quaver beaming in these examples seems to be related to a particular feature of the movement and can be grouped into two kinds:

a) leaping quavers, indicating lively execution/staccato articulation-e.g. WTC I, Fg.3 (ex.3), Pr.14, Pr.15, Pr.21; Goldberg Variations, vars. 28 and 29.

b) quavers on a repeated note or a step-wise progression, indicating plodding mood/slower pulse-e.g. BWV 621, 638, 639 from the Orgelüchlein, the andante section of BWV 826/1, Invention 15, WTC I, Pr.12, Pr.16 (ex.4); WTC II: Pr.20.

[insert ex.3]

Ex.3 Fugue 3 in C\# major, WTC I, autograph (Staatsbibliothek zu Berlin, Mus. ms. Bach P 415): opening

[insert ex.4]

Ex.4 Prelude 16 in G minor, WTC I, autograph (Staatsbibliothek zu Berlin, Mus. ms. Bach P 415): opening

It is striking that Bach chose shorter quaver beams for these two pieces with such diametrically contrasting characters, as if placed at the two extremes of Bach's musical norms, i.e. indicating 'exceptions' from his tempo ordinario. ${ }^{16}$

\footnotetext{
${ }^{16}$ For the discussion of Bach's tempo ordinario and the issue of inconsistency in Bach's notation, see Robert Marshall, 'Bach's Tempo ordinario: A Plaine and Easie Introduction to the System', Performance Practice Review, xiii/1 (2008), pp. 1-33, esp. at pp. 4-5.
} 
The great majority of cases, however, belong to the second and third scenarios, 'musical beaming' and 'unintelligible beaming' in which both beam types appear within the same movement. Bach’s decisions may be explained as being influenced by musical reasons, external factors such as spatial constraints (e.g. thick and crowded texture) or time-related factors (e.g. fatigue, boredom or excitement may have affected the way in which he wrote out the music), as summarised in table 3. The most intriguing among these situations is when the distinction between extended and default quaver beams appears to coincide with specific motifs or figures, which could be considered indicative of phrasing and articulation.

Table 3 Possible reasons behind Bach's use of two quaver beam types

[insert table 3]

\section{(1) DISTINGUISHING SUBJECTS AND EPISODES}

Let us return to ex.1 to examine Bach's beaming practice more closely, tables 4 and 5 . The quaver beams in the fugue subject are almost always joined together as ...... while those appearing in episodes tend to be given in the broken, default form $(. . . .$.$) . With regard to$ the six repeated quavers in the fugue subject, on the one hand, there is every reason to suspect that Bach intended to write them under one beam: thirteen of the total of sixteen instances are written as extended beams, which is statistically significant $(16: 3=81 \%)$; the three instances of split beaming (shown in bold in the 4th column and commented in the 5th column of table 4) seem to result from exceptional circumstances (and not the examples of 'unintelligible beaming'). However, although the continuous quaver motion in the episodes, derived from the figure in the bass of bar 9, appears less uniform in manner, a certain rationale may be detected: when the figure is treated melodically, as in the first episode, it is notated in extended form, and when the figure assumes a stronger harmonic role, as in the cadential passages, it tends to appear in the short, default form. The same observation holds true for the B-minor Fugue of WTC I (ex.2): while the quavers that are treated in imitation (such as those in bars 7-8, 24-26a) are beamed in groups of four, those appearing in the context of harmonic shifts (as those in bars 17-20, 26b-27) are presented in groups of two. It is therefore reasonable to infer that Bach distinguished between the two types of notating quavers on the grounds of their meaning and function within the piece.

Table 4 Bach's beaming of the six repeated quavers in the subject entries of Fugue 16 in G minor, WTC II (C) The British Library Board, Add. MS 35021, f.12)

[insert table 4]

Table 5 Bach's beaming of quavers in the episodes of Fugue 16 in G minor, WTC II (C The British Library Board, Add. MS 35021, f.12) 
[insert table 5]

(2) DistingUISHING CONTRASTING MOTIFS WITHIN FUGUE SUBJECTS

Both examples examined thus far concerned contrasting beaming practices between subject entries and episodes. The next instances concern the use of the two beam types to delineate the treatment of the material of the fugue subject in different fugal devices. The most compact example is Fugue in C major (WTC I), which contains both practices within the fugue subject, splitting it into a head and tail motive and leaving only one beat of neutral space between them (see ex.5).

[insert ex.5]

Ex.5 Fugue 1 in C, WTC I, autograph (D-B, Mus. ms. Bach P 415): first three systems (bars 1-10)

Here the head motifs $(\% \cdot \odot)$ are mostly written in extended beams, whereas the tail motifs $\left(\bullet . \_\right)$always have the short, default beam. Table 6 summarises their locations in the piece together with possible explanations for any abnormalities. Of the 26 occurrences of the head motif in this fugue, six occur either between beats 2 and 3 of the bar or over a bar line, where the extended beam could not be used (shown in bold in the 3rd column). ${ }^{17}$ Of the remaining 20 occurrences, four have the anomalous default form (shown in italic in the 4th column) and hence require scrutiny. Two of these, found in bars 5 and 10 respectively, may have been caused by the splitting of the bar over two systems in Bach's exemplar, while the beam form of the remaining two could have been compromised due to their function as stretto comes of the entries that belong to those six mentioned earlier. It may therefore be safely concluded that the distinction between the two beam forms in this fugue was executed with reasonable consistency (head 20:4 = 80\%; tail 23:0 = 100\%), which is significant, and suggests that Bach indeed had a system.

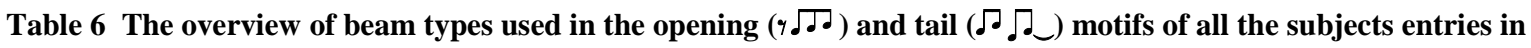
Fugue 1 in C major, WTC I, in Bach's autograph manuscript (Staatsbibliothek zu Berlin, Mus. ms. Bach P 415)

[insert table 6]

(3) DISTINGUISHING CONTRASTING MOTIFS FROM SUBJECTS TO COUNTERSUBJECTS

An example of the two beam types used for contrasting between the material of the subject and countersubject is Fugue 16 in G minor (WTC I), which uses the extended beam for the head motif of the subject $(\% \cdot \bullet)$, while the default beam is used for the tail of the

\footnotetext{
${ }^{17}$ See note 14.
} 
countersubject ( $\because \cdot \bullet$, derived by inverting the head motif), leaving two bars (or eight beats) of neutral space between them (see ex.6). The contrasting quaver beams are examined in tables 7 and 8.

[insert ex.6]

Ex.6 Fugue 16 in G minor, WTC I, autograph (Staatsbibliothek zu Berlin, Mus. ms. Bach P 415): first two systems (bars 1-7)

From table 7, it is clear that Bach wrote the head motif in the uniform shape of $\% \cdot \bullet$, with the exception of two instances of default beaming located immediately after a page break, where slips of the pen were more likely to occur; ${ }^{18}$ furthermore, the default beams do not start with a quaver rest but a note, making the entries somewhat indistinct. The second of these (bar $23 \mathrm{~A}$ ) is decorated with semiquavers, the notation of which is in Bach's norm (cf. table 2, 3rd row). Statistically, sixteen out of eighteen entries use extended beams, which is very significant $(18: 16=89 \%)$.

The notation of the tail motif is summarised in table 8. Statistically, nine out of ten use default beaming (90\%), which is equally consequential. The sole exception, found in bar 6 in the soprano, is difficult to explain. Bach may have confused it with the codetta figure of bar 4 as a notational reference.

Table 7 Bach's beaming of the head motif ( 4 $/$ ) of the subject in Fugue 16 in G minor, WTC I (autograph) [insert table 7]

Table 8 Bach's beaming of the tail motif $\left(\left\ulcorner\int\right.\right.$ ) of the countersubject in Fugue 16 in G minor, WTC I (autograph) [insert table 8]

\section{(4) MARKING AND ARTICULATING CADENTIAL PASSAGES}

Extending the observation to non-thematic areas of the composition, one can also find examples of Bach's exceptional use of short, default beams with prominent harmonic shifts, most notably in cadential passages. Numerous instances are found in the B-minor Fugue of WTC I, bar 23 (ex.2, 6th system, bar 3), among others. Two further examples may be drawn from the original print of the Goldberg Variations (1741) for which Bach presumably produced the no longer extant Stichvorlage. Illustrated in ex.7 are the final two systems of the Aria containing bars 27-32. In this 3/4-time movement, Bach regularly uses the extended beam $(\ldots \ldots)$ with the sole exception of the penultimate bar, in which he seems to have used the default beam to articulate the harmonic shifts of $\mathrm{V}-\mathrm{I}-\mathrm{V}$ before finally settling on I in the last bar.

\footnotetext{
${ }^{18}$ See, for example, notational corrections at similar points following page breaks in Prelude in C major (barring error), Fugue in G minor (clef error) and Prelude in B minor (note-value error) in the autograph of WTC II (The British Library London, Add. MS. 35021).
} 
[insert ex.7]

Ex.7 Goldberg Variations: Aria (bars 27-32) in the original print of 1741: short beams in the penultimate bar to articulate the cadence?

[insert ex.8]

Ex.8 Goldberg Variations: Variation 14 (bars 1-9) in the original print of 1741: to indicate the hemiola in bars 6-7?

Similarly, in Variation 14 (ex.8), the unique beam pattern in bars 6-7 of the RH staff looks as if it was meant to indicate the hemiola $(\ldots \ldots . . . \ldots .$.$) in the first major cadence at bar 8$.

(5) REFLECTING THE CHANGE OF MOOD / MODE?

Looking further away from the systematically distinguished quaver beams within pieces, we find an interesting case in the G-minor Prelude of WTC I (ex.9), in which the extended beams are used as exceptions in bars 4 and 7-8. The two isolated instances seem as if Bach redirected his attention from the harmonic shifts of each beat to the exploration of melodic freedom at these moments. The longest spell of extended beams, where the piece explores the relative major key, coincides with the melodic interest manifested in the step-wise motion of the inner part.

The observations made in relation to exx.7-9 support the notion that Bach responded musically to the content as he was writing it down on paper, whether the focus of his engagement was the development of a melodic organism or the strengthening of the harmonic pulse at cadential points; evidence of this is captured in the form of two distinct types of 'musical' quaver beams.

[insert ex.9]

Ex.9 Prelude 16 in G minor, WTC I (autograph): extended beams are found in bar 4 (tenor) and bars 7-8 (alto)

\section{Questions}

\section{(1) CONFLICTS OF INTEREST AND BACH'S PRIORITIES}

Up to this point, our discussion has focused on examples that reveal Bach's two contrasting beaming practices clearly coinciding with either the constructional elements of the fugues or his more general musical responses. In numerous other examples little rationale for Bach’s choice of beaming practices can be found, hence referred to as 'unintelligible beaming'. In my previous study, I ascribed these anomalies partially to Bach's less-considered decisions at the time he wrote out the piece afresh, and partially to Bach's reverting to default beaming as normal practice. ${ }^{19}$ Surely there is room for more rational explanations.

\footnotetext{
${ }^{19}$ Tomita, 'Reading Soul from Manuscripts’, pp.19 and 40.n.7.
} 
At this point, let us return to Fugue in B minor of WTC I, in which we witnessed the extended beams being initially employed for the notation of the fugue subject, but not maintained consistently from the fourth entry onwards. The way in which Bach wrote these quavers, especially in bar 14 (ex.2, 4th system, bar 1), in which the upper voices cross, hints that he felt it impractical to write extended beams due to spacial constraints. Examining them from a broader perspective, however, another possible reason for not pursuing notational consistency emerges. Table 9 captures Bach's choice of beaming in all five sections (a-e) of all the subject entries, including the false and incomplete ones. At a glance it is clear that Bach abandoned the use of extended beams when writing out the fourth entry.

Table 9 Fugue 24 in B minor, WTC I (autograph) - the beam types in the five sections of all the subject entries in the strength of greys: dark (extended) and light (default); incomplete and false entries are indicated by square brackets

[insert table 9]

In addition, the majority of the subject entries appear in the lower spectrum of the texture: ten of the thirteen entries are in the lowest part $(13: 10=77 \%)$. This is reminiscent of the texture in the episodes (esp. bars 17-20; 26-29; 65-68), which use the default beams. The lack of consistency from the viewpoint of the distinction between subject and episode may be attributed to Bach's practice of using default beams for the texture in which the bass part takes charge of harmonic shift. Are we witnessing Bach's priorities reflected in his notational procedures, whereby the musical events at local level take precedent over formulaic issues? If so this may suggest a category of 'priority' within 'musical beaming'. What implications does this have for our interpreting Bach’s compositional thinking?

(2) BACH'S RESPONSES TO THE DENSITY OF MUSICAL ACTIVITIES

Yet when we examine the many other cases in which Bach reverted to his initial decision of using the extended beam, the proposed theory above proves to be insufficient. Consider the case of the D-minor Fugue of WTC II (ex.10), transmitted in the hand of Bach’s second wife, Anna Magdalena.

\section{[insert ex.10]}

Ex.10 Fugue 6 in D minor, WTC II in the hand of Anna Magdalena Bach (@ The British Library Board, Add. MS 35021, f.4v)

She is one of the very few copyists who appears to have imitated Bach's handwriting down to the most minute of details. ${ }^{20}$ In this fugue Bach chose the extended beam for the

\footnotetext{
${ }^{20}$ See Yo Tomita, ‘Anna Magdalena as Bach’s copyist’, Understanding Bach, ii (2007), pp. 59-76.
} 
chromatically descending motif of the subject in the first half of the fugue (bars 1-13); in the second half (bars 14-27), where the fugue begins to explore the stretto and inversion techniques, Bach switched to default beaming. There is no textural issue with the bass line carrying the harmonic shifts in this fugue. Why did Bach change his mind halfway through? Could it be due to the increased density of musical activities? Such an observation is reasonably compatible with what we found in bar 15 of the Fugue in B minor of WTC I, where the piece reaches an early climax with the soprano entry completing the exposition. Does this imply that the change in the type of quaver beam indicates musical intensity reaching the maximum level at which was able Bach to handle multiple melodic motions, and the beaming a means to clarify the texture for the performer? Or does this only affect Bach's ability to write out his music, and not necessarily that he felt the same while performing his music?

\section{Summary}

The discussion with the supporting data documented in tables 1-10 above reveals emerging patterns of Bach's beaming habits. ${ }^{21}$ When writing out music, Bach distinguished two types of quaver beams - extended and default; most of the time he knew when to use each type, depending on the mood or character of the piece. He seldom used the default beam exclusively in a single movement; but when he did, he chose it with clear intent as exceptions to convey either lively character (ex.3) or plodding mood (ex.4). More often he used both types in the same piece to discreetly convey the finer nuances of the musical discourse, be it to distinguish the character of motifs and figures (exx.1-2 and 5-6), to structurally articulate cadential passages using default (ex.7) or semi-extended beams (ex.8), or to indicate an increased attention in a local passage with extended beams (ex.9). The discussion also considered the instances where conflicts of interest and Bach's priorities in the music resulted in the choice that contradicts the broader trend (table 9), and which reveal the threshold of musical intensity when the density of musical activities forced Bach to compromise his usual notational preference (ex.10).

Obstacles to our understanding what Bach intended by his quaver beaming remain. Other considerations may have influenced Bach to exploit quaver beaming in particular ways, including for example the repertoire on which young Bach taught himself to write music 'properly', and there are further situations where Bach applied the two types of quaver beams

\footnotetext{
${ }^{21}$ In addition a more comprehensive commentary of all the movements of the WTC is provided in the Appendix of Tomita, 'Reading soul from manuscripts', pp. 30-40.
} 
in multiple contexts, thus causing their significance to become confused and unclear. ${ }^{22}$ By analogy one can see that the two quaver-beam types resemble italic or bold in wordprocessing: they tend to be abused if one is unfamiliar with the rules for their usage. It may be the case that Bach, who became aware of the choice of two beam types to indicate extra meaning, did not give himself precise rules but only a rough understanding of how these beam types should be used.

The observation and categorisation of Bach's beaming is a new approach in Bach studies that helps reveal how Bach responded to his pieces in performance. Given that the process of writing music cannot be directly translated into performance clues, his quaver beaming nonetheless sheds light on how he engaged with and perceived his music from motivic to structural levels. The analysis so far shows that Bach’s beaming was intentional, and indicative of the manner in which he would have his works performed. Deciphering these performance clues is a research topic that merits further attention.

\footnotetext{
${ }^{22}$ See for example the anomalous use of quaver beams in the A-minor Prelude of WTC II as discussed in Tomita, 'Reading soul from Manuscripts', pp. 19-20.
} 


\title{
Deciphering J. S. Bach's performance hints hidden in his quaver beams
}

\author{
Yo Tomita
}

\section{Tables}

Table 1 Bach's convention of quaver beaming

\begin{tabular}{|c|c|c|}
\hline Time-signature & Bach's normal beaming (extended) & Exceptional (default) \\
\hline $2 / 4$ & $\bar{\ldots}(\varphi, \bar{\ldots} ; ., \%)$ & ...(\%॰..; ..๑ \\
\hline $3 / 4$ & $\ldots \ldots \ldots(\%, \ldots \ldots ;, \ldots \ldots \varphi)$ & $\ldots \ldots \ldots(\varphi \circ \ldots \ldots ; \ldots \ldots \odot \varphi)$ \\
\hline $4 / 4$ & $\ldots \ldots \ldots$ & $\ldots \ldots \ldots$ \\
\hline $6 / 16$ & ... & $\therefore$. \\
\hline $12 / 16$ & ....... & $\therefore$. D. D. \\
\hline
\end{tabular}

Table 2 Bach's notation of quaver-semiquaver/demisemiquaver combinations in 3/4 time

\begin{tabular}{|c|c|c|}
\hline Bach's normal beaming & Exceptional & Reasons for exceptions \\
\hline ...... & ...... & $\begin{array}{l}\text { no plain quavers (or the result of } \\
\text { revision from } \ldots \ldots \text { ?) }\end{array}$ \\
\hline . $\equiv \ldots . \bar{\equiv}$ & no exception & \\
\hline$\ldots \ldots$ & $\ldots \ldots$ & the result of revision from $\ldots \ldots$ ? \\
\hline$\ldots \ldots$ & $\ldots \ldots \ldots$ & as above \\
\hline
\end{tabular}

Table 3 Possible reasons behind Bach's use of two quaver beam types

\begin{tabular}{l|ll}
\hline Reason & Bach's norm (extended beams) & Exceptions (default beams) \\
\hline Musical attention & horizontal (i.e. melodic interest) & vertical (i.e. harmonic shifts) \\
Musical material & motifs & cadential figures \\
Texture & thin & thick (and congested) \\
Position within the piece & early & late \\
\hline
\end{tabular}


Table 4 Bach's beaming of the six repeated quavers in the subject entries of Fugue 16 in G minor, WTC II (C) The British Library Board, Add. MS 35021, f.12)

\begin{tabular}{lllll}
\hline Bar & Voice & Entry type & Beaming & Comments on exceptions \\
\hline 4 & T & Subject & $1 \times 6$ & \\
8 & A & Answer & $1 \times 6$ & \\
12 & S & Subject & $2: 4+2$ & Bach's model had the system change between beats 2 and 3? \\
23 & T & Answer & $1 \times 6$ & \\
31 & A & Subject & $2: \mathbf{2 + 4}$ & page break in the middle, hence unavoidable \\
35 & S & Subject & $1 \times 6$ & \\
39 & B & Answer & $1 \times 6$ & \\
48 & T & Subject & $1 \times 6$ & \\
& A & (added 3rds) & $3: \mathbf{2 + 2 + 2} \quad$ to avoid collision with the soprano \\
54 & S & Subject & $1 \times 6$ & \\
& A & (added 6ths) & $1 \times 6$ & \\
62 & B & Subject & $1 \times 6$ & \\
& T & (added 3rds) & $1 \times 6$ & \\
72 & S & Subject & $1 \times 6$ & \\
& T & (added 6ths; variant) & $1 \times 6$ & \\
82 & B & Subject & $1 \times 6$ & \\
\hline
\end{tabular}

Table 5 Bach’s beaming of quavers in the episodes of Fugue 16 in G minor, WTC II (ㄷ The British Library Board, Add. MS 35021, f.12)

\begin{tabular}{|c|c|c|c|}
\hline Episodes (bars) & Quavers found (voice) & Beaming & Comments \\
\hline $1(17-20)$ & bars $17(\mathrm{~S}), 18(\mathrm{~A})$ & $1 \times 4$ & $\begin{array}{l}\text { imitation of the leaping figure of bar } 9 \text { in the } \\
\text { upper parts }\end{array}$ \\
\hline $2(24-28)$ & bars 24-27 (B) & 3: $2+2+2$ & $\begin{array}{l}\text { repetition of the leaping figure of bar } 9 \text { in the } \\
\text { bass, modulating in the circle of } 5 \text { ths }\end{array}$ \\
\hline $3(40-45)$ & bar 44 (B) & 3: $2+2+2$ & cadential motion \\
\hline $4(49-51)$ & $\mathrm{n} / \mathrm{a}$ & $\mathrm{n} / \mathrm{a}$ & $\mathrm{n} / \mathrm{a}$ \\
\hline $5(55-59)$ & bar 55 (B) & $3: 2+2+2$ & cadential motion \\
\hline $6(63-67)$ & $\begin{array}{l}\text { bars } 63 \text { (A / B), } 65 \text { (B), } \\
66(\mathrm{~T} / \mathrm{B})\end{array}$ & $\begin{array}{l}\text { mixture of } 1 \times 4 \\
\text { and } 3: 2+2+2\end{array}$ & cadential motion \\
\hline
\end{tabular}

Table 7 Bach's beaming of the head motif ( $\%$ J) of the subject in Fugue 16 in G minor, WTC I (autograph)

\begin{tabular}{|c|c|c|c|c|}
\hline Bars & Beats & Voice & Beam type & Possible explanation for the abnormality; (additional notes) \\
\hline 1 & $1-2$ & A & extended & \\
\hline 2 & $3-4$ & $\mathrm{~S}$ & extended & \\
\hline 5 & $1-2$ & B & extended & \\
\hline 6 & $3-4$ & $\mathrm{~T}$ & extended & \\
\hline 7 & $1-2$ & $\mathrm{~S}$ (false entry) & extended & (modified shape) \\
\hline 12 & $1-2$ & A & extended & \\
\hline 13 & $3-4$ & B & extended & \\
\hline 15 & $1-2$ & $\mathrm{~S}$ & extended & \\
\hline 17 & $1-2$ & B & extended & (joined with preceding quaver: 4 quavers beamed: $\ldots$ ) \\
\hline 17 & $3-4$ & A & extended & \\
\hline 20 & $1-2$ & B & extended & (joined with preceding quaver: 4 quavers beamed: ... \\
\hline 21 & $3-4$ & $\mathrm{~S}$ & default & $\begin{array}{l}\text { joined with preceding quaver }(. \cdot .) \text {, immediately after page } \\
\text { break }\end{array}$ \\
\hline 23 & $1-2$ & A (decorated) & default & the first quaver note is decorated as two semiquavers $(\bar{\sigma} \cdot$. $)$ \\
\hline 28 & $1-2$ & $\mathrm{~S}$ & extended & (joined with preceding quaver: 4 quavers beamed: . .• ) \\
\hline 28 & $3-4$ & $\mathrm{~T}$ & extended & \\
\hline 29 & $1-2$ & B & extended & \\
\hline 31 & $3-4$ & A & extended & \\
\hline 33 & $1-2$ & $\mathrm{~T}$ & extended & \\
\hline
\end{tabular}


Table 8 Bach's beaming of the tail motif $(\ulcorner\cdot$ ) of the countersubjects in Fugue 16 in G minor, WTC I (autograph)

\begin{tabular}{rllll}
\hline Bars & Beats & Voice & Beam type & Possible explanation for the abnormality; (additional notes) \\
\hline 3 & $3-4$ & A & default & \\
6 & $1-2$ & S & extended & erroneous reference to the codetta $• .$. in bar 4? \\
7 & $3-4$ & B & default & \\
13 & $1-2$ & T & default & \\
14 & $3-4$ & T & default & \\
16 & $1-2$ & B & default & \\
18 & $1-2$ & S & default & (split by system break) \\
21 & $1-2$ & A & default & \\
22 & $3-4$ & B & default & \\
24 & $1-2$ & B (inversion) & default & (local cadence) \\
32 & $3-4$ & B & default & \\
34 & $1-2$ & B (modified) & default & (final cadence) \\
\hline
\end{tabular}

Table 9 Fugue 24 in B minor, WTC I (autograph) - the beam types in the five sections of all the subject entries in the strength of greys: dark (extended) and light (default); incomplete and false entries are indicated by square brackets

\begin{tabular}{|c|c|c|c|c|c|c|c|c|}
\hline Bar & Subject entries & (a) & (b) & (c) & (d) & (e) & Texture & Position \\
\hline 1 & Alto & & & & & & 1 & alone \\
\hline 4 & Tenor & & & & & & 2 & lowest \\
\hline 9 & Bass & & & & & & 3 & lowest \\
\hline 13 & Soprano & & & & & & 4 & top \\
\hline 16 & [Tenor] & & & & & & 4 & middle \\
\hline 19 & [Tenor] & & & & & & 4 & middle \\
\hline 21 & Alto & & & & & & $4 \rightarrow 3$ & middle \\
\hline 28 & [Tenor] & & & & & & 4 & middle \\
\hline 30 & Tenor & & & & & & $4 \rightarrow 3$ & lowest \\
\hline 34 & [Alto] & & & & & & 3 & middle \\
\hline 35 & [Soprano] & & & & & & 3 & top \\
\hline 38 & Bass & & & & & & 4 & lowest \\
\hline 41 & [Soprano] & & & & & & 3 & top \\
\hline 42 & [Alto] & & & & & & 3 & middle \\
\hline 43 & [Bass] & & & & & & 3 & bottom \\
\hline 44 & Tenor & & & & & & 4 & low (lowest except pedal) \\
\hline 47 & Bass & & & & & & $4 \rightarrow 3$ & lowest \\
\hline 53 & Tenor & & & & & & 3 & lowest \\
\hline 57 & Bass & & & & & & 3 & lowest \\
\hline 60 & Tenor & & & & & & 3 & lowest \\
\hline 70 & Bass & & & & & & 4 & lowest \\
\hline 74 & [Alto] & & & & & & $4 \rightarrow 5$ & middle \\
\hline
\end{tabular}




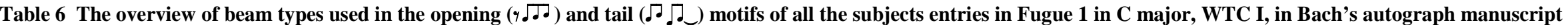
(Staatsbibliothek zu Berlin, Mus. ms. Bach P 415)

\begin{tabular}{|c|c|c|c|c|c|c|}
\hline Bar & Voice & $\begin{array}{l}\text { Beat location } \\
\text { of head motif }\end{array}$ & Type & Possible explanation for the abnormality; (supplementary comments) & $\begin{array}{l}\text { Beat location } \\
\text { of tail motif }\end{array}$ & Comments \\
\hline 1 & A & $1-2$ & extended & & $4-1$ & \\
\hline 2 & S & 3-4 & extended & & $2-3$ & \\
\hline 4 & $\mathrm{~T}$ & $1-2$ & extended & & $4-1$ & \\
\hline 5 & $\mathrm{~B}$ & 3-4 & default & quavers in the tenor are tied, hinting the model had a system break? & $2-3$ & \\
\hline 7 & S & $1-2$ & extended & & $4-1$ & \\
\hline 7 & $\mathrm{~T}$ & $2-3$ & default & (split by system break) & $1-2$ & \\
\hline 9 & A & $1-2$ & extended & & $4-1$ & \\
\hline 10 & B & $3-4$ & default & split by system break & $2-3$ & \\
\hline 10 & A & $4-1$ & default & & $3-4$ & \\
\hline 12 & $\mathrm{~T}$ & $1-2$ & extended & & $4-1$ & \\
\hline 14 & A & $1-2$ & extended & & $4-1$ & \\
\hline 14 & $\mathrm{~T}$ & $2-3$ & default & & $1-2$ & \\
\hline 15 & $\mathrm{~B}$ & $1-2$ & extended & & $4-1$ & \\
\hline 15 & $S$ & $3-4$ & extended & (incomplete entry) & $\mathrm{n} / \mathrm{a}$ & \\
\hline 16 & $\mathrm{~S}$ & $2-3$ & default & & $1-2$ & \\
\hline 16 & A & $3-4$ & default & entry preceded by a tied note $\left(\_. . \cdot\right)$ instead of a rest - stretto comes of $16 \mathrm{~S}$ (default) & $2-3$ & \\
\hline 17 & $\mathrm{~T}$ & $1-2$ & extended & & $4-1$ & \\
\hline 17 & $\mathrm{~B}$ & $3-4$ & $\mathrm{n} / \mathrm{a}$ & head modified (starting with $•$ instead of $\bullet^{-}$) & $2-3$ & \\
\hline 19 & $\mathrm{~T}$ & $1-2$ & extended & & $4-1$ & split by page break \\
\hline 19 & A & $2-3$ & default & & $1-2$ & \\
\hline 20 & $\mathrm{~B}$ & $3-4$ & extended & (incomplete entry; preceded by a note instead of a rest) & $\mathrm{n} / \mathrm{a}$ & \\
\hline 20 & S & 4-1 & default & & $3-4$ & \\
\hline 21 & $\mathrm{~T}$ & $3-4$ & default & entry preceded a note $(. \cdot . \cdot)$ instead of a rest-stretto comes of $20 \mathrm{~S}$ & $2-3$ & \\
\hline 24 & $\mathrm{~T}$ & $1-2$ & extended & (entry preceded by a tied note instead of a rest) & $4-1$ & \\
\hline 24 & A & 3-4 & extended & (entry preceded by a tied note instead of a rest) & $2-3$ & \\
\hline 24 & S & 4-1 & default & (entry preceded by a note instead of a rest) & $\mathrm{n} / \mathrm{a}$ & modified \\
\hline
\end{tabular}


Yo Tomita, Deciphering J. S. Bach’s performance hints hidden in his quaver beams: Illustrations, p. 1

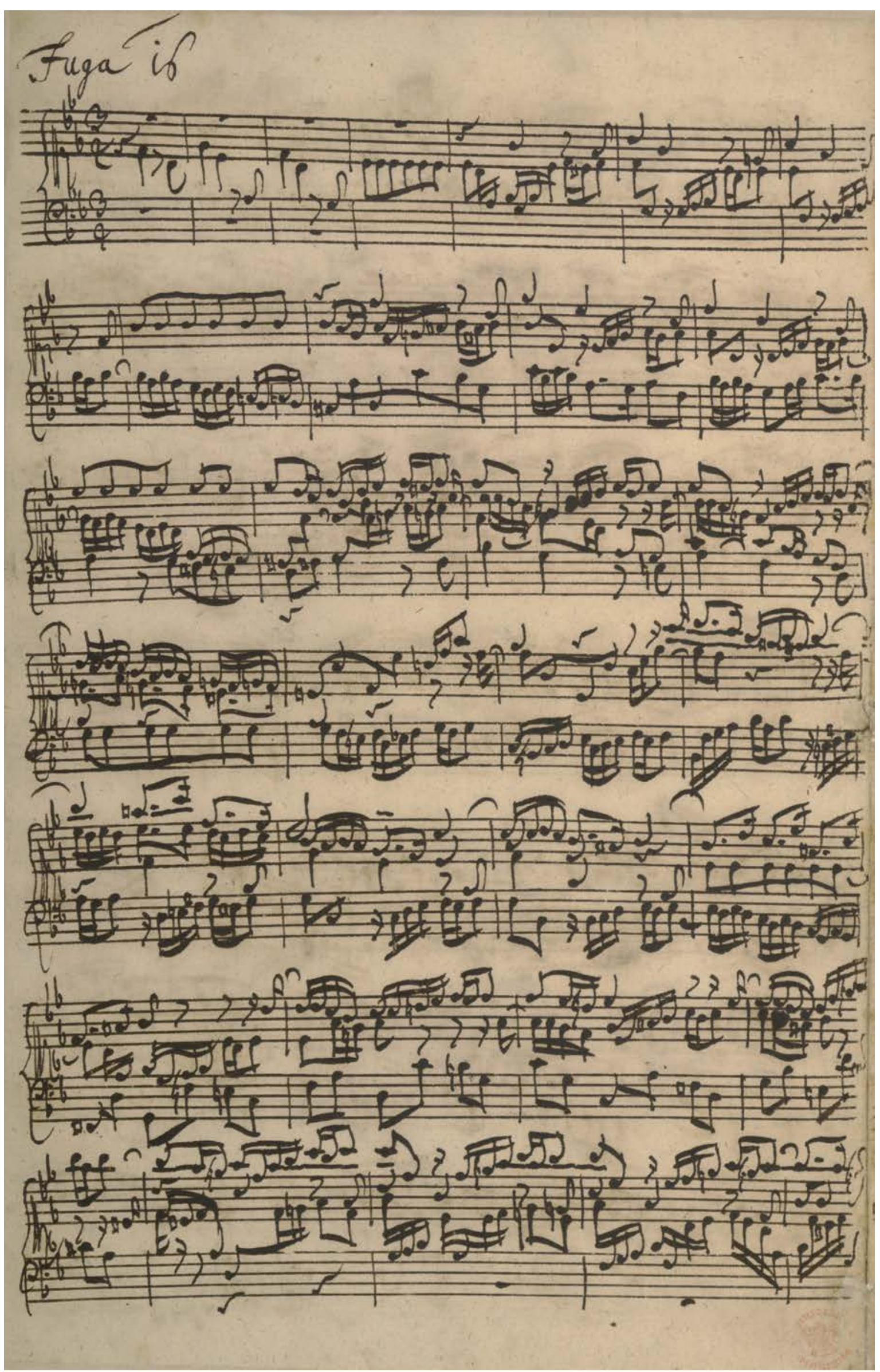

Ex.1 Fugue 16 in G minor, WTC II, autograph (GB-Lbl, Add. MS 35021, f.12v): bars 1-31 
Yo Tomita, Deciphering J. S. Bach's performance hints hidden in his quaver beams: Illustrations, p. 2

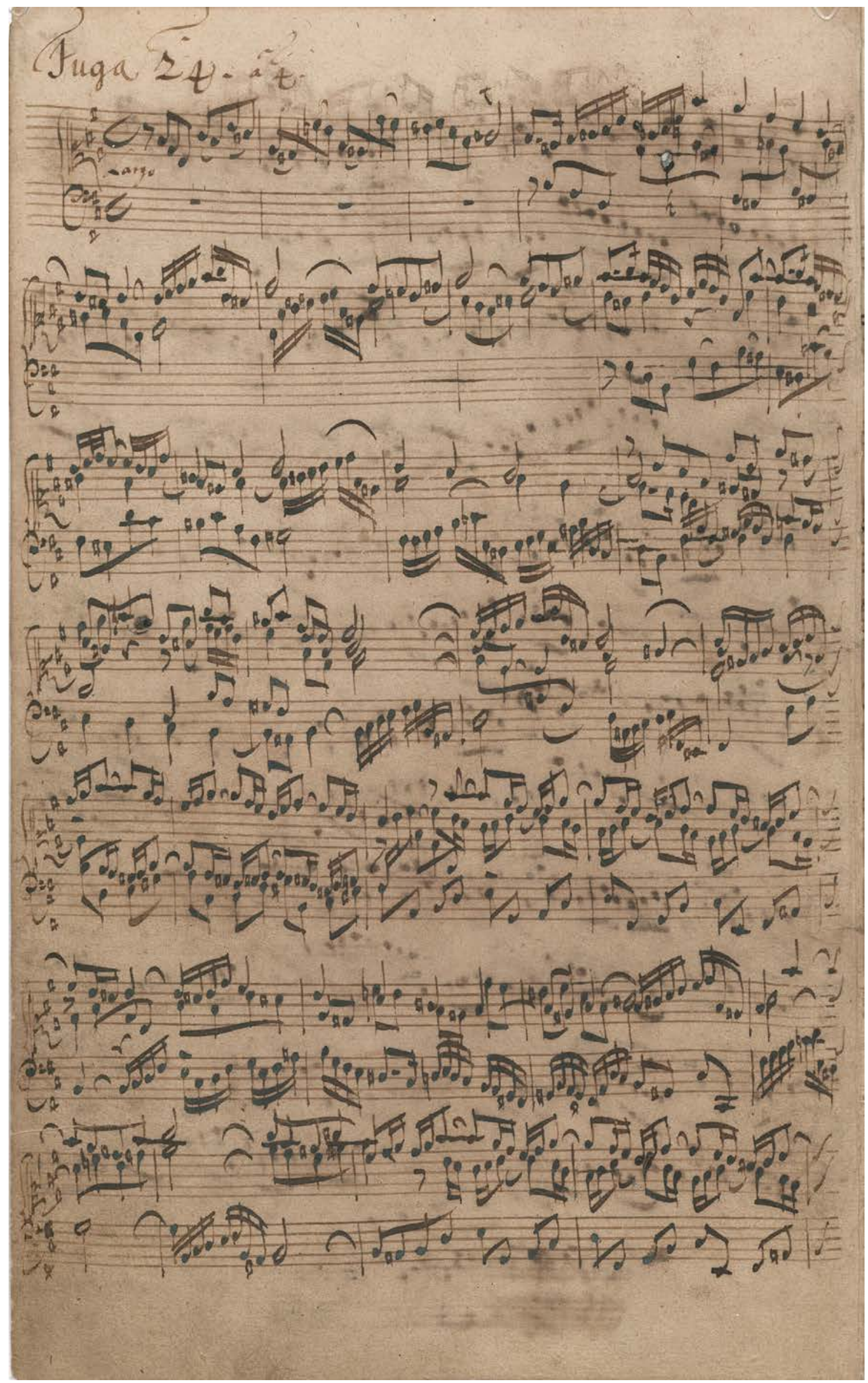

Ex.2 Fugue 24 in B minor, WTC I, autograph, (D-B, Mus. ms. Bach P 415, f. 44v): bars 1-27 
Yo Tomita, Deciphering J. S. Bach's performance hints hidden in his quaver beams: Illustrations, p. 3

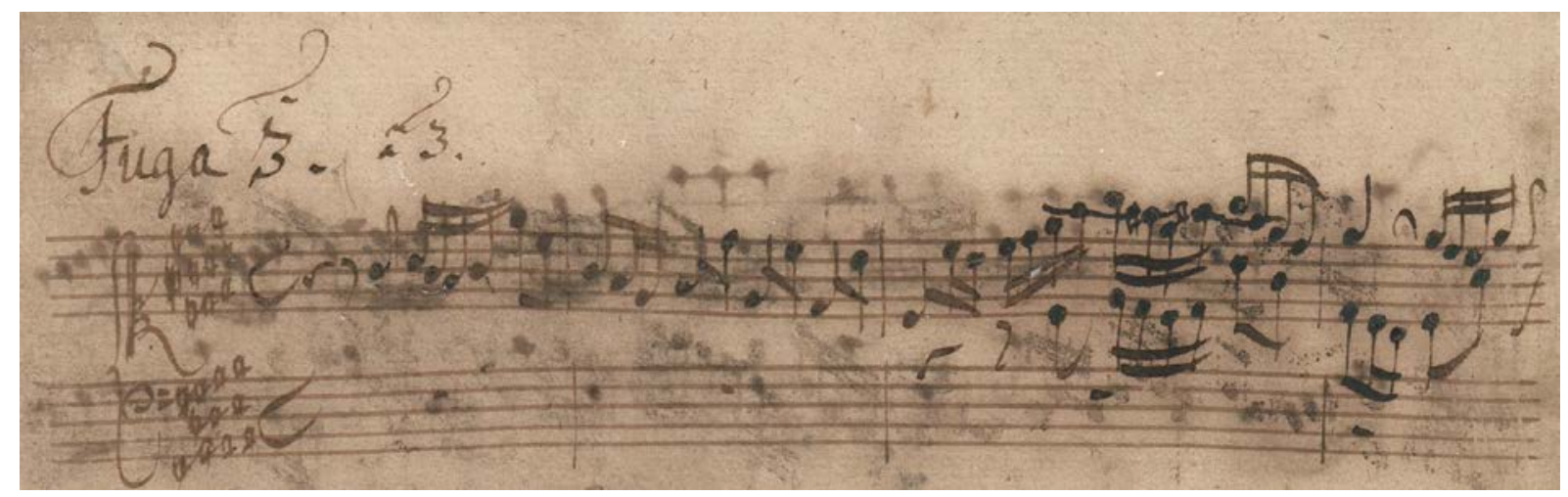

Ex.3 Fugue 3 in C\# major, WTC I, autograph (D-B, Mus. ms. Bach P 415): opening

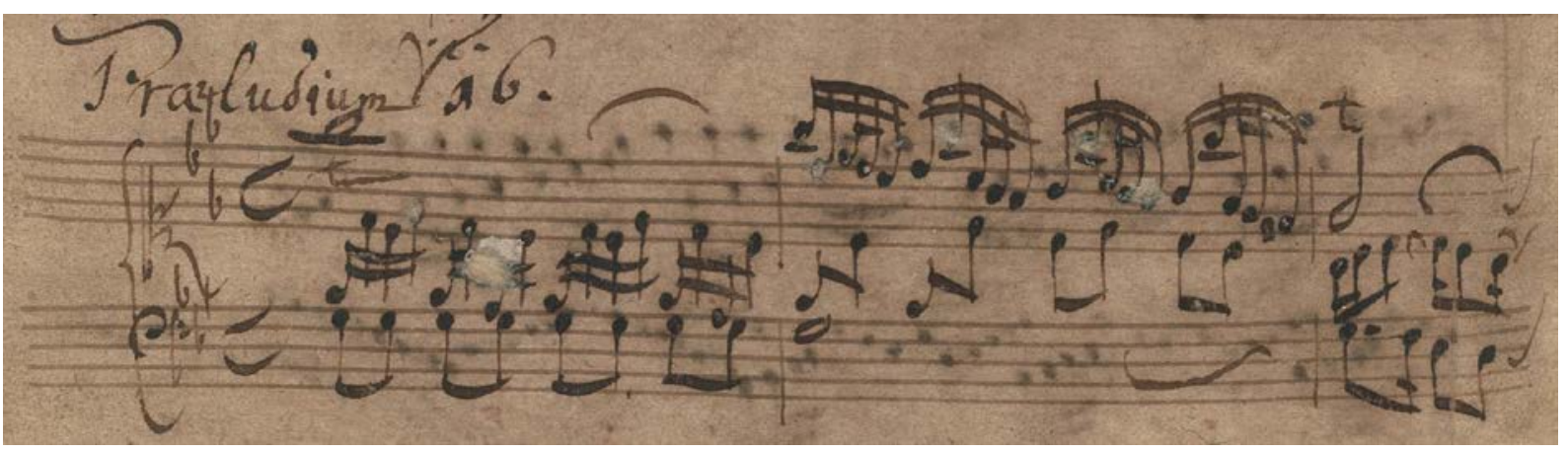

Ex.4 Prelude 16 in G minor, WTC I, autograph (D-B, Mus. ms. Bach P 415): opening

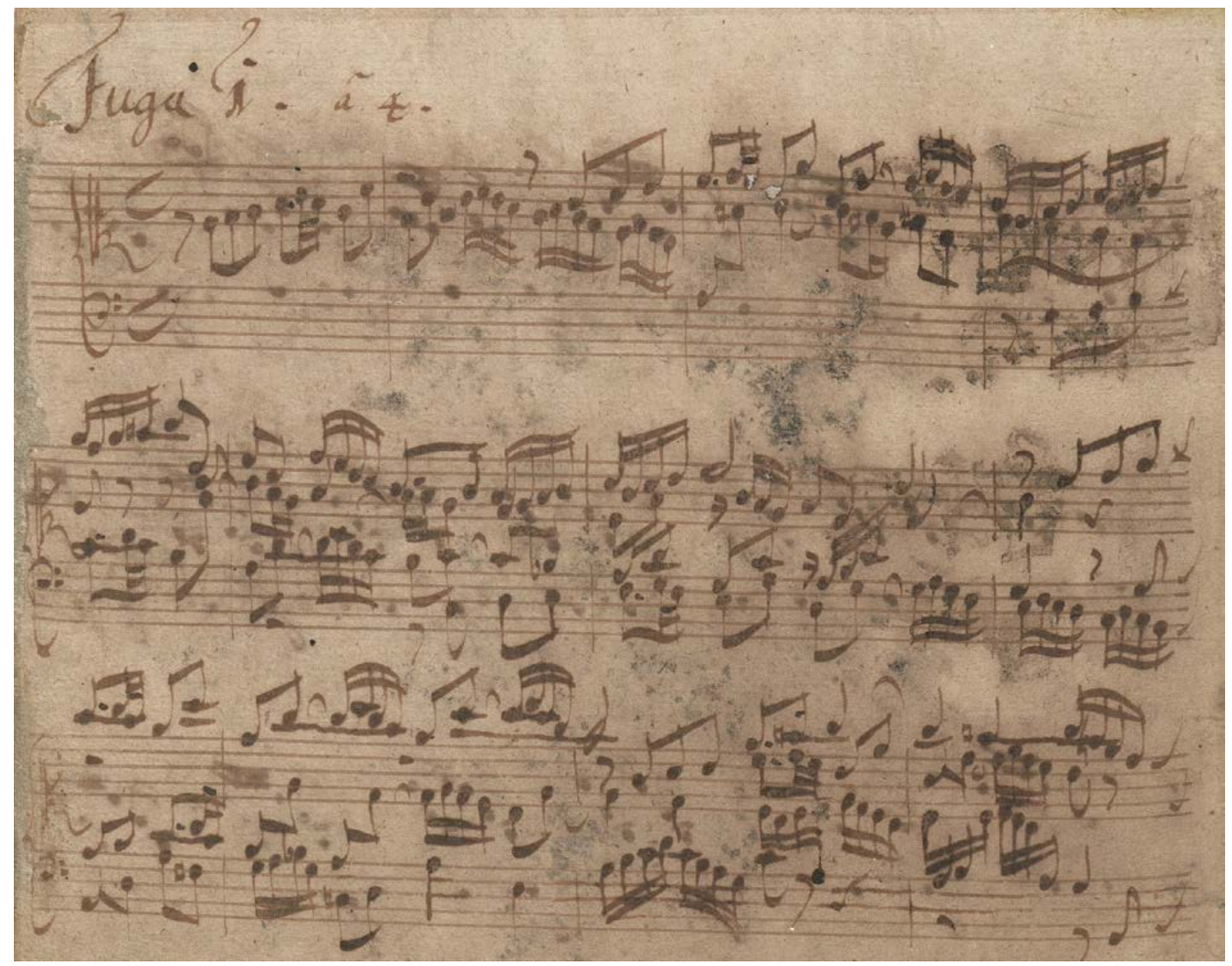

Ex.5 Fugue 1 in C, WTC I, autograph (D-B, Mus. ms. Bach P 415): first three systems (bars 1-10) 
Yo Tomita, Deciphering J. S. Bach’s performance hints hidden in his quaver beams: Illustrations, p. 4

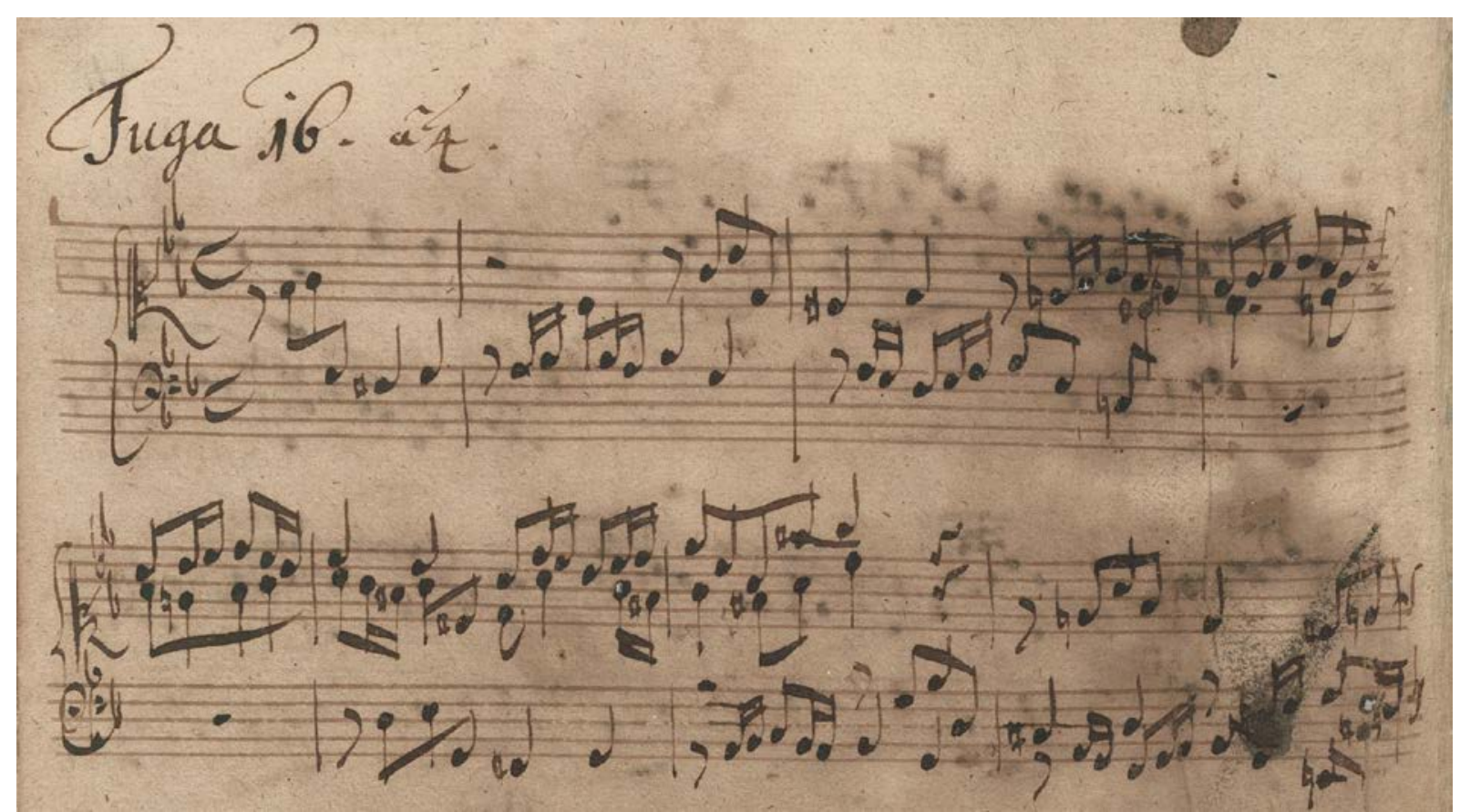

Ex.6 Fugue 16 in G minor, WTC I, autograph (D-B, Mus. ms. Bach P 415): first two systems (bars 1-7)

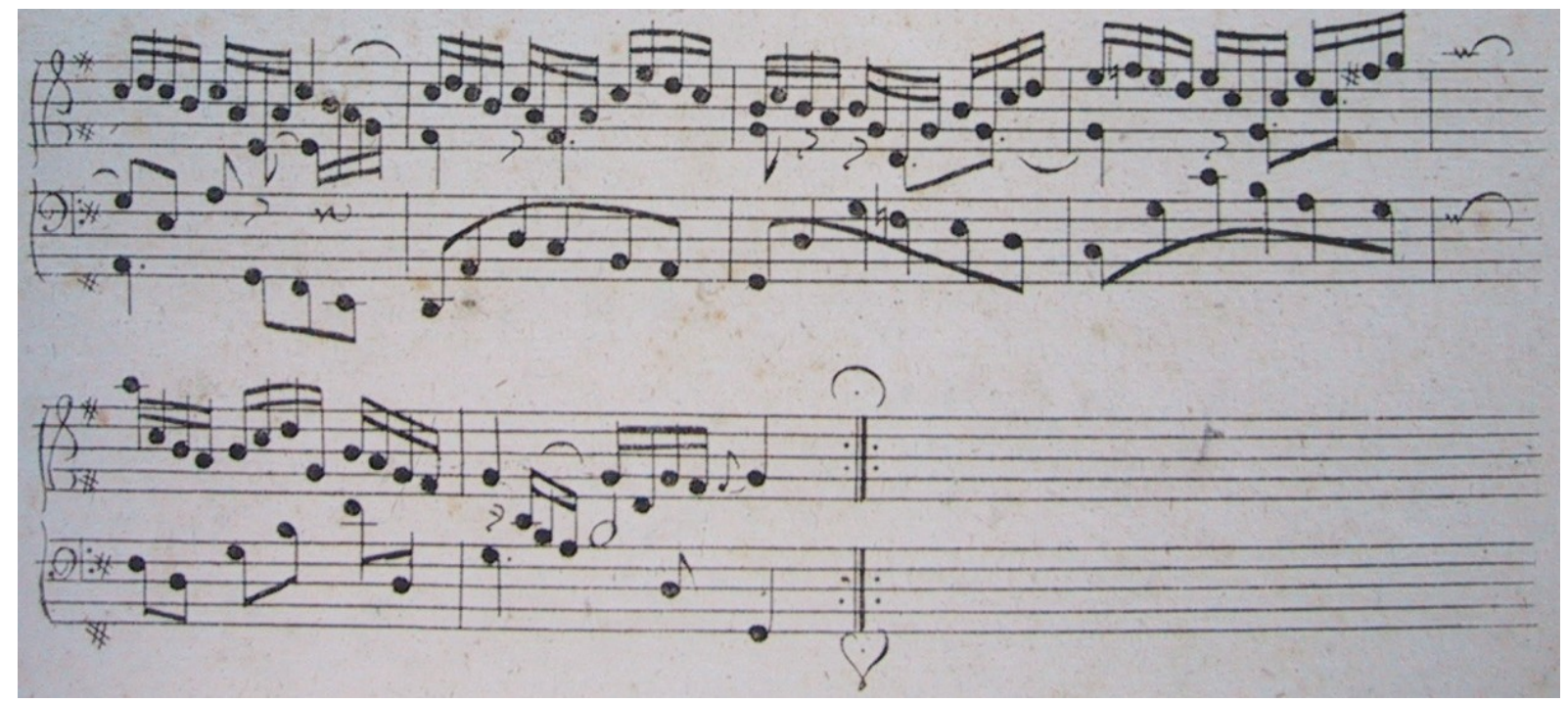

Ex.7 Goldberg variations: Aria (bars 27-32) in the original print of 1741: short beams in the penultimate bar to articulate the cadence? 
Yo Tomita, Deciphering J. S. Bach’s performance hints hidden in his quaver beams: Illustrations, p. 5

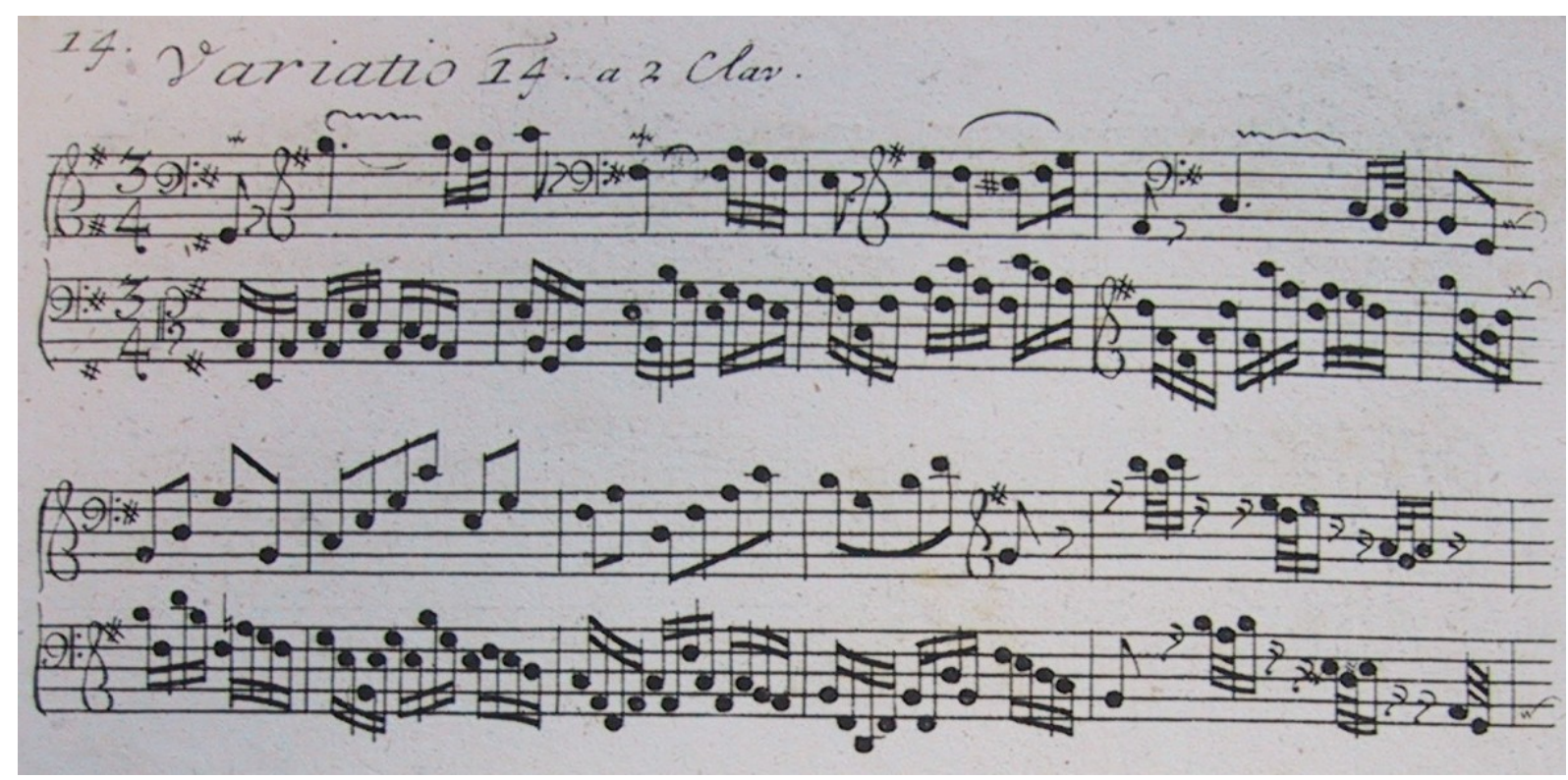

Ex.8 Goldberg variations: Variation 14 (bars 1-9) in the original print of 1741: to indicate the hemiola in bars 6-7?

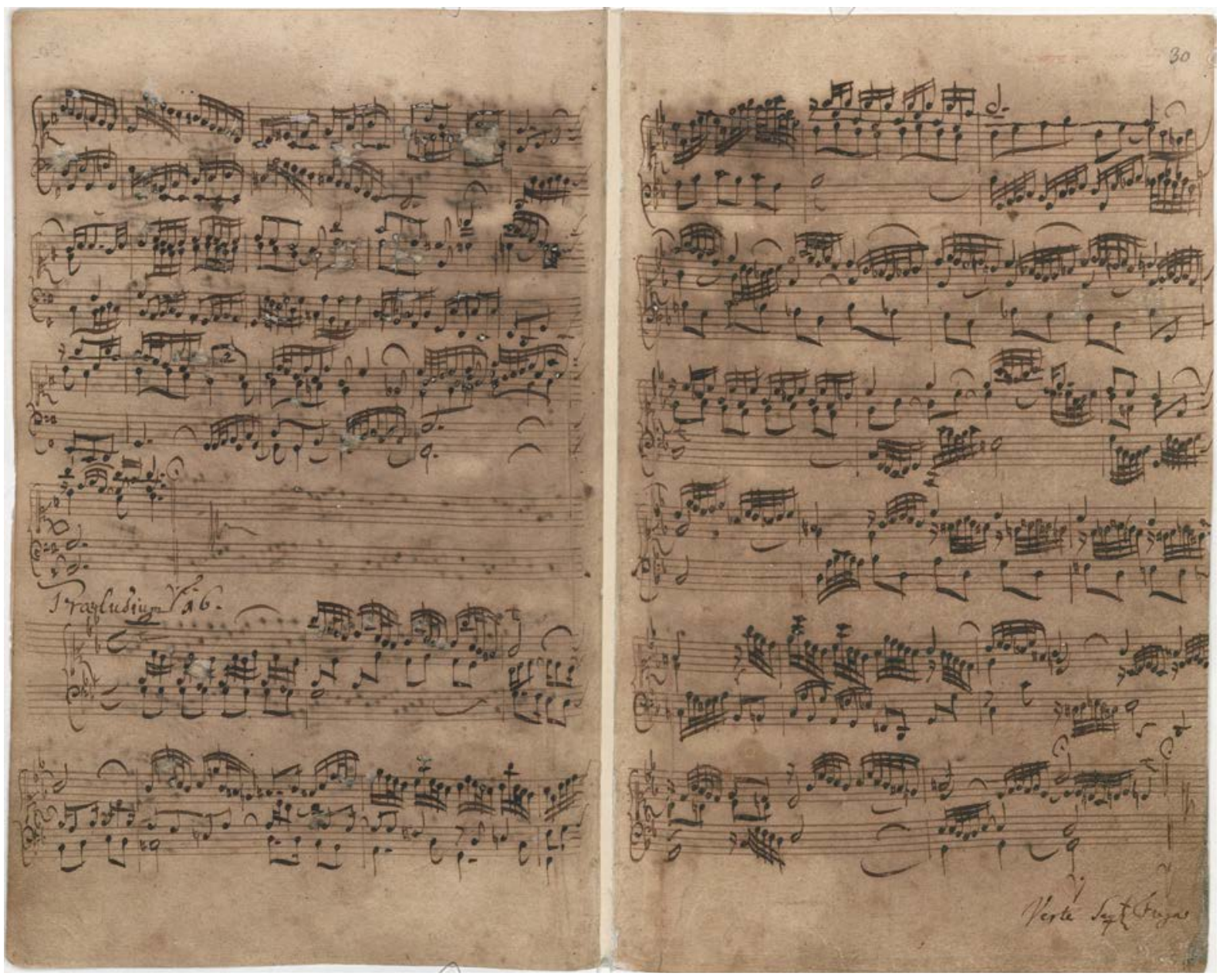

Ex.9 Prelude 16 in G minor, WTC I (autograph): extended beams are found in bar 4 (tenor) and bars 7-8 (alto) 
Yo Tomita, Deciphering J. S. Bach’s performance hints hidden in his quaver beams: Illustrations, p. 6

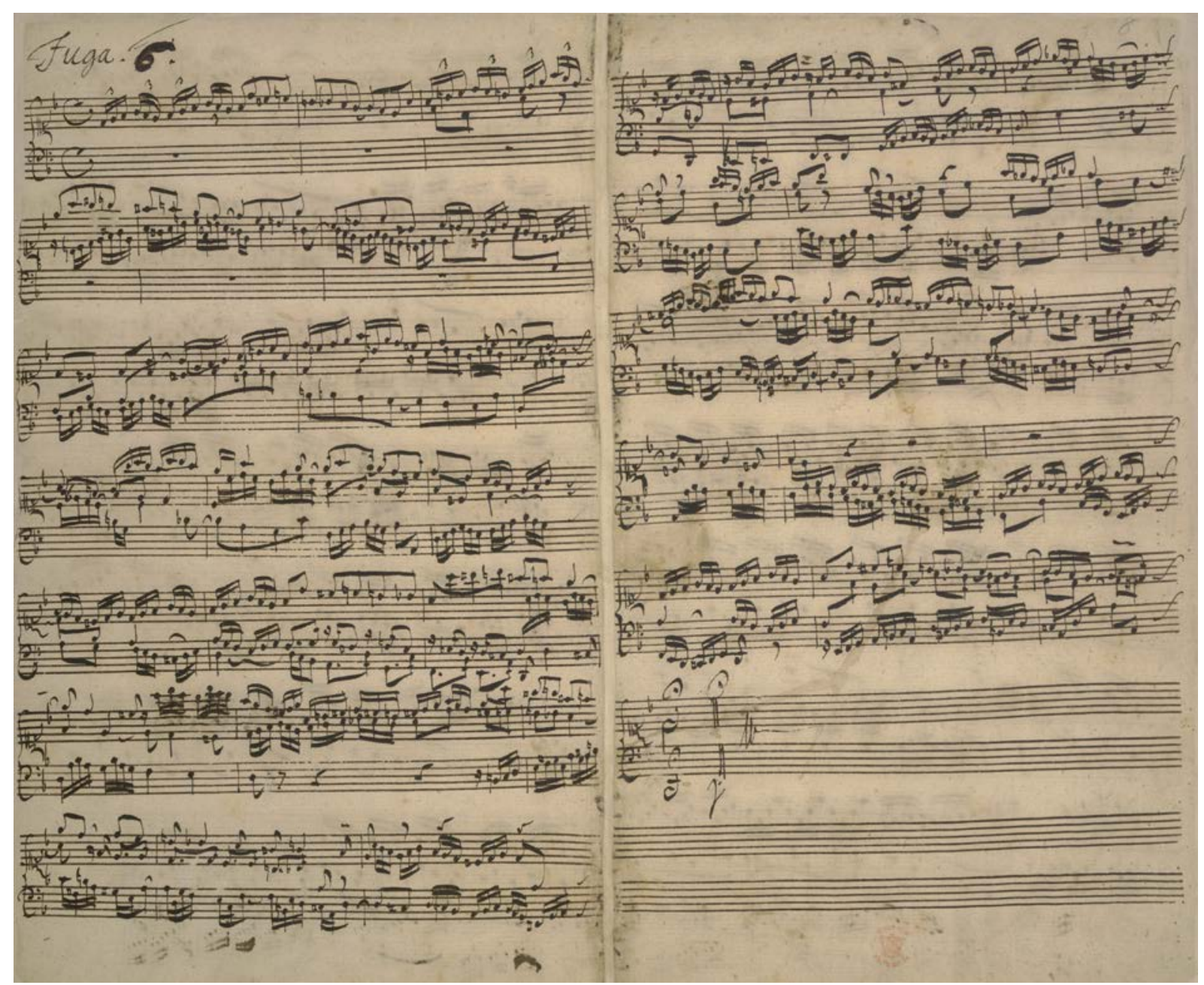

Ex.10 Fugue 6 in D minor, WTC II in the hand of Anna Magdalena Bach (GB-Lbl, Add. MS 35021, f.4v) 